\title{
Serum a-klotho concentrations during preimplantation can predict aging or quality of human oocytes and clinical pregnancy rates
}

\author{
Takashi Takemura* and Midori Okabe
}

\begin{abstract}
Background: To discover simple biomarkers to evaluate the aging or quality of human oocytes and clinical pregnancy rates is needed. However, the association among serum a-klotho concentrations during preimplantation, the aging or quality of human oocytes and clinical pregnancy rates has not been investigated.

Findings: The serum a-klotho concentrations during preimplantation decreased due to aging $(p<0.001)$, whereas the maturation rates of human oocytes $(p<0.001)$ and the fertilization rates $(p<0.001)$ improved in association with increased serum a-klotho concentrations. Furthermore, multiple logistic regression analysis showed that the clinical pregnancy rates were influenced by serum a-klotho concentrations during preimplantation $(p<0.001)$, the patient's age $(p=0.003)$, maturation rates of human oocytes $(p<0.001)$, fertilization rates $(p<0.001)$ and the serum $25(O H) D$ levels $(p<0.001)$ regardless of race $(p=0.29)$ and BMI $(p=0.96)$.
\end{abstract}

Conclusion: The serum a-klotho concentrations during preimplantation would be a simple biomarker in order to predict the aging or quality of human oocytes and clinical pregnancy rates.

Keywords: Serum a-klotho concentrations, Serum $25(\mathrm{OH}) \mathrm{D}$ levels, Aging or quality of human oocytes

\section{Background}

A simple biomarker to evaluate the aging or quality of human oocytes and clinical pregnancy rates is required. On the other hand, since klotho protein was detected in 1997 (Kuro-o et al. 2007), klotho is intensively researched. Klotho is an ageing-modulated protein expressed mainly in the kidneys and choroid plexus (Wolf et al. 2014). Furthermore, $\alpha$-klotho is known as an anti-aging molecule. The $\alpha$-klotho gene mutant mice have been shown to have short life-spans and multiple aging phenotypes analogous to those observed in humans, such as skin atrophy, osteoporosis, ectopic calcification, atherosclerosis, and pulmonary emphysema (Nakanishi et al. 2015). Moreover, increases in $\alpha$-klotho concentrations in human serum

*Correspondence: reprogramming@gakushikai.jp

Reproductive Medicine Institute Japan, Nakano-ku, Chuo, 3-37-12, Tokyo 164-0011, Japan positively promote human health (Yamazaki et al. 2010). For examples, $\alpha$-klotho is known as cardio-renal protective protein (Lee et al. 2014). Serum $\alpha$-klotho concentration may be novel and useful early markers of diabetic renal injury (Lee et al. 2014). Therefore, increases in $\alpha$-klotho concentrations in human serum positively may improve the aging or quality of human oocytes and clinical pregnancy rates. However, an association between serum $\alpha$-klotho concentrations during preimplantation and the aging or quality of human oocytes has not been investigated.

Hochbaum et al. (2011) previously identified klo-2, a homologue of $\alpha$-klotho gene, as one candidate direct target of DAF-12 (a homologue of vitamin D receptor) in model organism Caenorhabditis elegans (Hochbaum et al. 2011). On the other hand, the association studies between serum $\alpha$-klotho concentrations and vitamin D were conducted (Koyama et al. 2015; Shardell et al. 
2015). However, an association between serum $\alpha$-klotho concentrations during preimplantation and vitamin $\mathrm{D}$ in infertile patients has not been investigated.

\section{Methods}

\section{Study population}

Healthy non-pregnant women participated in the present study (Table 1). Written informed consent was obtained from subjects prior to enrollment. From March 2012 to April 2015, a total of 633 women were enrolled.

\section{Measurement of serum a-klotho levels}

Blood samples were drawn from a forearm vein in the morning after overnight fasting. Sera were obtained by centrifugation and immediately stored at $-30{ }^{\circ} \mathrm{C}$. Serum $\alpha$-klotho concentrations were evaluated during preimplantation using the human soluble $\alpha$-klotho Assay Kit (TAKARA BIO Inc., Japan).

\section{Measurement of serum $25(\mathrm{OH}) \mathrm{D}$ levels and pregnancy}

Serum $25(\mathrm{OH})$ D levels were measured using enzymeimmunoassay (Immunodiagnostic Systems Inc., Fountain Hills, AZ, USA). Furthermore, pregnancies were based on detection of a gestational sac (GS).

\section{The ovarian stimulation protocol}

Eligible patients in the present study were treated with the ovarian stimulation regimen (mild stimulation protocol). In the mild stimulation protocol, patients received clomiphene citrate at $100 \mathrm{mg} /$ day from day 3 to day 7 followed by human chorionic gonadotropin (hMG) injections $1-5$ times. $0.25 \mathrm{mg}$ of gonadotropin-releasing

Table 1 Demographic and clinical characteristics of the patients

\begin{tabular}{ll}
\hline Characteristics & Value \\
\hline No. patients & 633 \\
Mean maternal age (range) (years) & $36.84(30-45)$ \\
Race-no. (\%) & \\
Asian & $443(70 \%)$ \\
White & $178(28.1 \%)$ \\
Black & $12(1.9 \%)$ \\
Current smoker-no. (\%) & $0(0 \%)$ \\
Intracytoplasmic sperm injection (ICSI) (\%) & $633(100 \%)$ \\
Mean serum alpha-klotho concentrations & $593.14(123.77-1227.1)$ \\
(pg/mL) (range) & $39.8(0-100)$ \\
Mean maturation rate (range) (\%) & $37.9(0-100)$ \\
Mean fertilization rate (range) (\%) & 33 \\
Pregnancy rate (\%) & $21.4(16.9-31.6)$ \\
Mean body mass index (BMI) & $74.8(30-144)$ \\
Mean serum 25 (OH) D levels (nmol/L) (range) &
\end{tabular}

hormone (GnRH) antagonist was started every $24 \mathrm{~h}$ when the leading follicle diameter reached $14 \mathrm{~mm}$. With transvaginal ultrasound monitoring, when the diameter of a dominant follicle reached $18 \mathrm{~mm}$, all the patients were administered with hCG (5000 IU) intramuscularly. Transvaginal sonographically guided oocyte retrieval was performed $36 \mathrm{~h}$ after hCG injection.

\section{The evaluation of oocyte maturation rates and the fertilization rates}

In the samples of oocytes from the women, the presence of matured oocytes at metaphase II (MII) was confirmed. The oocytes with polar body were regarded as mature MII oocytes, and were used for normal intracytoplasmic sperm injection (ICSI). Furthermore, success rates of maturation and fertilization were determined under microscopic observation (Olympus IX71, Japan) by two embryologists at our institute. Moreover, maturation rates were assessed by the number of MII oocytes/total number of oocytes used for in vitro maturation at 24 or $48 \mathrm{~h}$. Fertilization rates were assessed with the number of $2 \mathrm{PN}$ oocytes/total number of oocytes used for ICSI at 24 or $48 \mathrm{~h}$ after ICSI.

\section{Approval of institutional review board}

We, authors, confirm that the work described has been carried out in accordance with The Code of Ethics of the World Medical Association (Declaration of Helsinki). Furthermore, all of the experiments were approved by the institutional review board at Reproductive Medicine Institute Japan.

\section{Statistical analyses}

All of the statistical tests were performed using Dr. SPSS II for Windows (SPSS Japan, Inc., Tokyo), and significance was defined as $\mathrm{p}<0.05$ (two-tailed). Continuous values were expressed as the mean values \pm standard deviation (SD). Statistical analyses were investigated by using single logistic regression analysis and multiple logistic regression analysis.

\section{Results}

\section{Demographic and clinical characteristics of the patients}

Demographic and clinical characteristics of the patients were shown as Table 1. Mean maternal age was 36.84 years (range $30-45$ ). All patients were treated by ICSI as assisted reproductive technology. Ovarian stimulation protocol was one (see "Methods" section). Pregnancy rates was $33.0 \%$. Furthermore, all patients were non-smoker. Moreover, Asian was $70.0 \%(\mathrm{n}=443)$, White was $28.1 \%(\mathrm{n}=178)$ and Black was $1.90 \%$ $(\mathrm{n}=12)$. 
Associations among serum a-klotho concentrations during preimplantation, the fertilization rates and the maturation rates

The serum $\alpha$-klotho concentrations during preimplantation were decreased by aging (Fig. 1, p < 0.001), while the maturation rates (Fig. 2, p < 0.001) and the fertilization rates (Fig. 3, p $<0.001$ ) were improved by

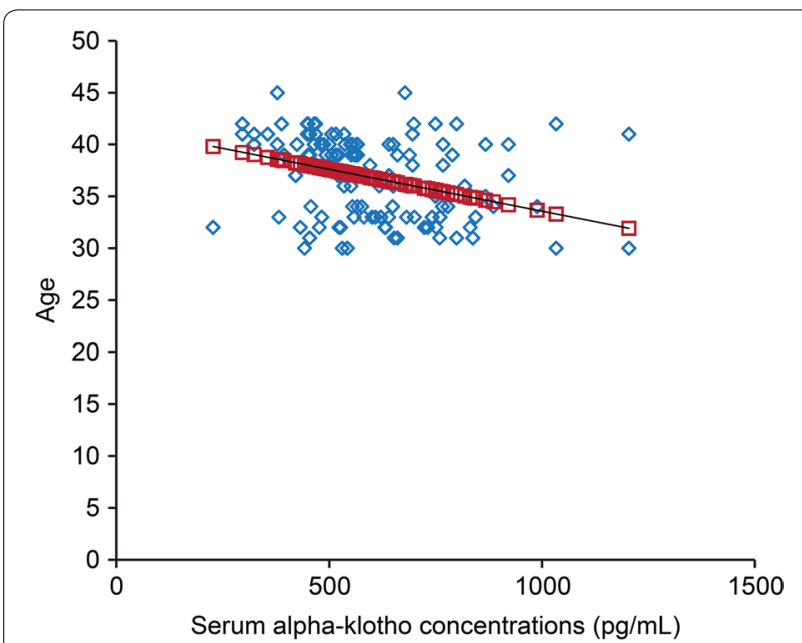

Fig. 1 An association between serum a-klotho concentrations during preimplantation and age. X-axis: serum a-klotho concentrations during preimplantation $(\mathrm{pg} / \mathrm{mL})$, $y$-axis: age

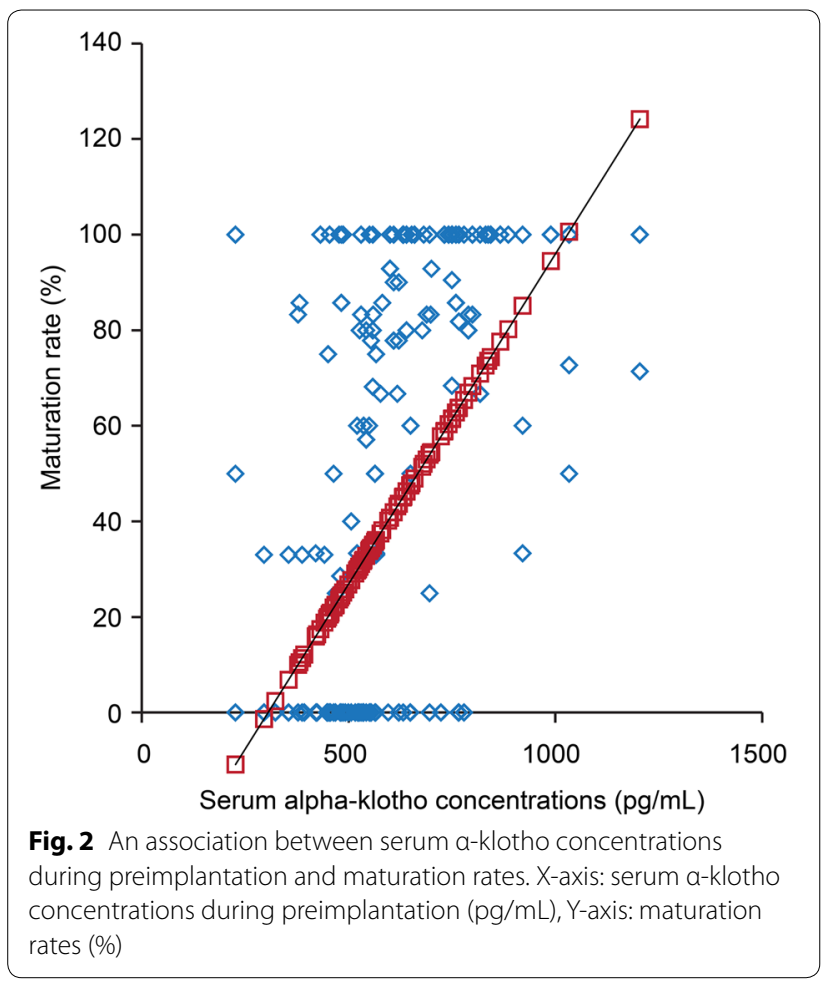

increasing of the serum $\alpha$-klotho concentrations during preimplantation.

\section{Associations among serum a-klotho concentrations} during preimplantation, the clinical parameters [BMI and serum $25(\mathrm{OH})$ D levels]

BMI was negatively associated with the serum $\alpha$-klotho concentrations during preimplantation (Fig. 4, p < 0.001).

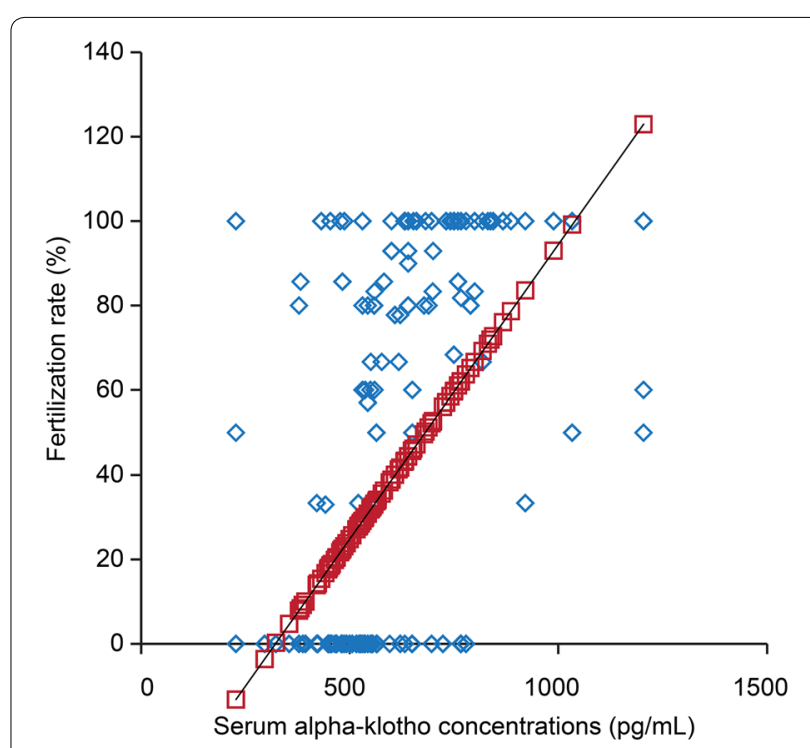

Fig. 3 An association between serum a-klotho concentrations during preimplantation and fertilization rates. X-axis: serum a-klotho concentrations during preimplantation $(\mathrm{pg} / \mathrm{mL})$, Y-axis: fertilization rates $(\%)$

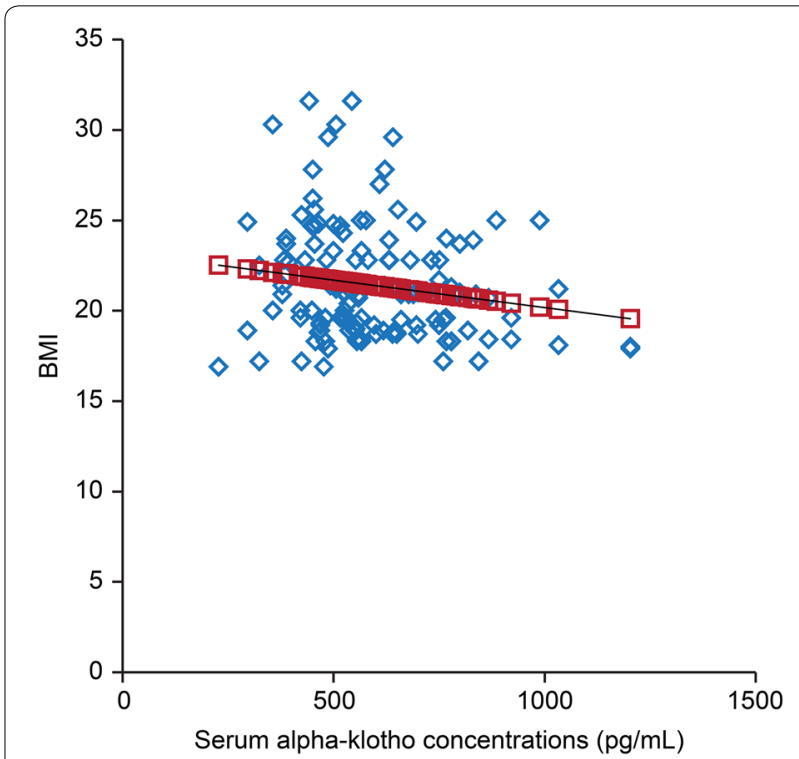

Fig. 4 Associations between serum a-klotho concentrations during preimplantation and BMI. X-axis: serum a-klotho concentrations during preimplantation $(\mathrm{pg} / \mathrm{mL})$, Y-axis: BMl 
Furthermore, the serum $25(\mathrm{OH})$ D levels were positively associated with the serum $\alpha$-klotho concentrations during preimplantation (Fig. 5, $\mathrm{p}<0.001$ ).

\section{Multiple logistic regression analysis}

Multiple logistic regression analysis (Table 2) showed that the clinical pregnancy rates were influenced by serum $\alpha$-klotho concentrations during preimplantation $(\mathrm{p}<0.001)$, the patient's age $(\mathrm{p}=0.003)$, maturation rates of human oocytes $(\mathrm{p}<0.001)$, fertilization rates $(\mathrm{p}<0.001)$ and the serum $25(\mathrm{OH})$ D levels $(\mathrm{p}<0.001)$ regardless of race $(\mathrm{p}=0.29)$ and BMI $(\mathrm{p}=0.96)$. After the multivariate analysis, the clinical pregnancy rates were positively associated with the patient's age, serum $\alpha$-klotho concentrations, maturation rates of human oocytes, fertilization rates and the serum $25(\mathrm{OH}) \mathrm{D}$ levels.

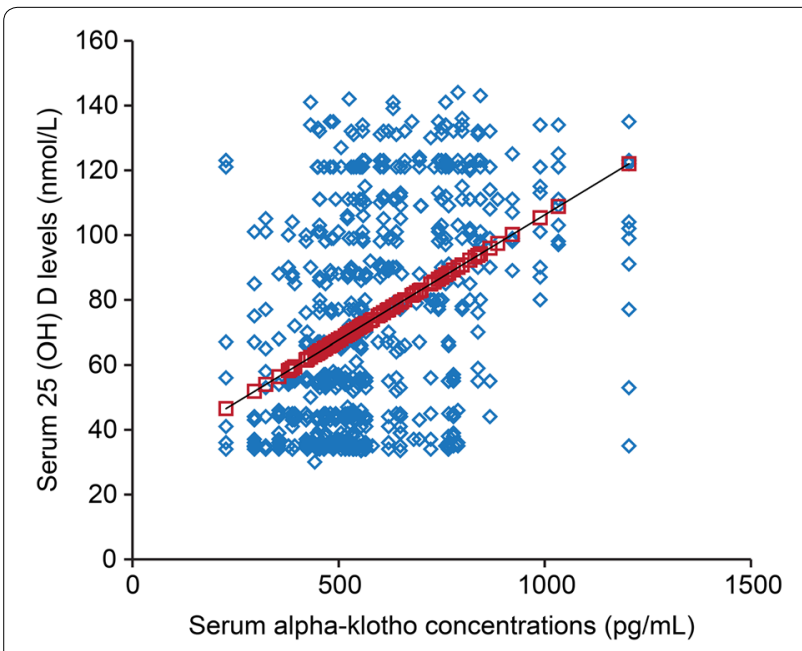

Fig. 5 Associations between serum a-klotho concentrations during preimplantation and serum $25(\mathrm{OH}) \mathrm{D}$ levels. X-axis: serum a-klotho concentrations during preimplantation $(\mathrm{pg} / \mathrm{mL})$, Y-axis: serum $25(\mathrm{OH})$ D levels

Table 2 Multiple logistic regression analysis

\begin{tabular}{lcc}
\hline & t value & p value \\
\hline Age & -2.95616 & 0.003232 \\
Serum alpha-klotho concentrations $(\mathrm{pg} / \mathrm{mL})$ & 10.5659 & $<0.0001$ \\
Maturation rate (\%) & 7.68942 & $<0.0001$ \\
BMl & -0.04677 & 0.962714 \\
Serum 25 (OH) D levels $(\mathrm{nmol} / \mathrm{L})$ & 6.220646 & $<0.0001$ \\
Race & -1.06139 & 0.288925 \\
Fertilization rate $(\%)$ & 6.789421 & $<0.0001$ \\
\hline
\end{tabular}

\section{Cutoff for alpha-klotho concentrations} during preimplantation that was correlating with clinical pregnancy rates

Mean serum alpha-klotho concentrations during preimplantation was $593.14 \mathrm{pg} / \mathrm{mL}$ in the present study. Furthermore, according to a previous report, $562 \mathrm{pg} / \mathrm{mL}$ in healthy adults $(\mathrm{n}=142$, mean) age 20 years old or over (Yamazaki et al. 2010). Therefore, when we considered $550 \mathrm{pg} / \mathrm{mL}$ a cutoff for alpha-klotho that was correlating with clinical pregnancy rates, with this cutoff value, $65.0 \%$ sensitivity and $54.0 \%$ specificity for prediction of pregnancy was achieved.

Furthermore, when we considered $600 \mathrm{pg} / \mathrm{mL}$ a cutoff for alpha-klotho that was correlating with clinical pregnancy rates, with this cutoff value, $81.0 \%$ sensitivity and $65.0 \%$ specificity for prediction of pregnancy was achieved.

Moreover, when we considered $700 \mathrm{pg} / \mathrm{mL}$ a cutoff for alpha-klotho that was correlating with clinical pregnancy rates, with this cutoff value, $70.0 \%$ sensitivity and $50.0 \%$ specificity for prediction of pregnancy was achieved.

Therefore, considering these factors, we considered $600 \mathrm{pg} / \mathrm{mL}$ a cutoff for alpha-klotho that was correlating with clinical pregnancy rates in the present study.

\section{Discussion}

The data of a report implicate DNA double-strand break (DSB) repair efficiency as an important determinant of oocyte aging in women (Titus et al. 2013). However, more simple biomarker in order to evaluate the aging or quality of human oocytes and clinical pregnancy rates is needed in the clinical setting. Furthermore, while current understanding of the molecular biology of the $\alpha$-klotho may offer new insights into its function and role in aging, the possibility of the serum $\alpha$-klotho concentrations during preimplantation in order to evaluate the aging or quality of human oocytes and clinical pregnancy rates has not been investigated. In this regard, our present prospective study is the first study reporting that the serum $\alpha$-klotho concentrations during preimplantation can predict the aging or quality of human oocytes and clinical pregnancy rates significantly. However, as pregnancy rate depend on many confounding factors, although we considered many confounding factors by multiple logistic regression analysis, further another factors should be considered.

On the other hand, the serum $25(\mathrm{OH})$ D levels were positively associated with the serum $\alpha$-klotho concentrations during preimplantation in the present study. Furthermore, the administration of 1,25- $(\mathrm{OH}) 2 \mathrm{D} 3$ induced the expression of klotho in the kidney in mice (Tsujikawa et al. 2003). Therefore, the serum $\alpha$-klotho concentrations during preimplantation may be improved by vitamin D supplementation. Further studies will be needed. 


\section{Conclusion}

In conclusion, the serum $\alpha$-klotho concentrations during preimplantation would be useful as a biomarker in order to predict the aging or quality of human oocytes and clinical pregnancy rates.

\section{Authors' contributions}

TT: Conception and design, provision of study material, data analysis and interpretation, manuscript writing, final approval of manuscript. MO: Provision of study material, data analysis and interpretation, manuscript writing, final approval of manuscript. Both authors read and approved the final manuscript.

\section{Acknowledgements}

We are very grateful to physicians and embryologists (data collection) at Reproductive Medicine Institute in Japan and USA. The present work was self-funding.

\section{Competing interests}

The authors declare that they have no competing interests.

Received: 21 July 2015 Accepted: 12 January 2016

Published online: 20 January 2016

\section{References}

Hochbaum D, Zhang Y, Stuckenholz C, Labhart P, Alexiadis V, Martin R, Knölker HJ, Fisher AL (2011) DAF-12 regulates a connected network of genes to ensure robust developmental decisions. PLoS Genet 7:e10021794

Koyama D, Sato Y, Aizawa M, Maki T, Kurosawa M, Kuro-O M, Furukawa Y (2015) Soluble a Klotho as a candidate for the biomarker of aging. Biochem Biophys Res Commun 467:1019-1025
Kuro-o M, Matsumura Y, Aizawa H, Kawaguchi H, Suga T, Utsugi T, Ohyama Y, Kurabayashi M, Kaname T, Kume E, Iwasaki H, lida A, Shiraki-lida T, Nishikawa S, Nagai R, Nabeshima YI (2007) Mutation of the mouse klotho gene leads to a syndrome resembling ageing. Nature 390:45-51

Lee EY, Kim SS, Lee JS, Kim IJ, Song SH, Cha SK, Park KS, Kang JS, Chung $\mathrm{CH}$ (2014) Soluble a-klotho as a novel biomarker in the early stage of nephropathy in patients with type 2 diabetes. PLoS One 9:e102984

Nakanishi K, Nishida M, Harada M, Ohama T, Kawada N, Murakami M, Moriyama T, Yamauchi-Takihara K (2015) Klotho-related molecules upregulated by smoking habit in apparently healthy men: a cross-sectional study. Sci Rep 5:14230

Shardell M, Semba RD, Kalyani RR, Hicks GE, Bandinelli S, Ferrucci L (2015) Serum 25-hydroxyvitamin D, plasma klotho, and lower-extremity physical performance among older adults: findings from the InCHIANTI study. J Gerontol A Biol Sci Med Sci 70:1156-1162

Titus S, Li F, Stobezki R, Akula K, Unsal E, Jeong K, Dickler M, Robson M, Moy F, Goswami S, Oktay K (2013) Impairment of BRCA1-related DNA doublestrand break repair leads to ovarian aging in mice and humans. Sci Transl Med 5:172ra21

Tsujikawa H, Kurotaki Y, Fujimori T, Fukuda K, Nabeshima Y (2003) Klotho, a gene related to a syndrome resembling human premature aging, functions in a negative regulatory circuit of vitamin D endocrine system. Mol Endocrinol 17:2393-2403

Wolf I, Shahmoon S, Ben Ami M, Levy-Shraga Y, Mazor-Aronovitch K, PinhasHamiel O, Yeshayahu Y, Hemi R, Kanety H, Rubinek T, Modan-Moses D (2014) Association between decreased klotho blood levels and organic growth hormone deficiency in children with growth impairment. PLoS One 9:e107174

Yamazaki Y, Imura A, Urakawa I, Shimada T, Murakami J, Aono Y, Hasegawa H, Yamashita T, Nakatani K, Saito Y, Okamoto N, Kurumatani N, Namba N, Kitaoka T, Ozono K, Sakai T, Hataya H, Ichikawa S, Imel EA, Econs MJ, Nabeshima Y (2010) Establishment of sandwich ELISA for soluble alphaKlotho measurement: age-dependent change of soluble alpha-Klotho levels in healthy subjects. Biochem Biophys Res Commun 398:513-518

\section{Submit your manuscript to a SpringerOpen ${ }^{\circ}$ journal and benefit from:}

- Convenient online submission

- Rigorous peer review

- Immediate publication on acceptance

- Open access: articles freely available online

- High visibility within the field

- Retaining the copyright to your article

Submit your next manuscript at $>$ springeropen.com 